\title{
Collective Batesian mimicry of ant groups by aggregating spiders
}

Short Title: Aggregation effects in mimicry

Ximena J Nelson ${ }^{1,2}$

Robert R Jackson ${ }^{1,3}$

${ }^{1}$ School of Biological Sciences, University of Canterbury, Private Bag 4800,

Christchurch, New Zealand

${ }^{2}$ Centre for the Integrative Study of Animal Behaviour, Macquarie University, Sydney, NSW 2109, Australia

${ }^{3}$ International Centre of Insect Physiology and Ecology (ICIPE), Thomas Odhiambo

Campus, P.0. Box 30 Mbita Point, Kenya

Correspondence: Ximena Nelson, 209 Culloden Rd, Marsfield 2122, NSW, Australia

Email: ximena.nelson@canterbury.ac.nz

Phone: 64-3-3642987 extn 4050

Fax: 64-3-3642590

Word count: 6974 
Many predators are averse to attacking ants and many palatable arthropods are Batesian mimics of ants. Here we consider whether aggregating Batesian mimics of ants can become more repelling to ant-averse predators by, as a group, resembling groups of ants (collective mimicry). Myrmarachne melanotarsa is a gregarious ant-like jumping spider (Salticidae) that resembles and associates with is Crematogaster sp. We used three large ant-averse salticids as predators in experiments. Besides M. melanotarsa and Crematogaster we used midges (Chaoborus sp.) and a small non-ant-like, but gregarious, salticid (Menemerus sp.) as prey. The predators readily attacked live midges and the nonant-like salticids presented singly or in groups but rarely attacked ants or ant mimics. Predators attacked ants and ant mimics presented in groups less often than they attacked solitary ants and ant mimics. In another experiment, motionless lures (groups of arthropods mounted in lifelike posture) were used. These findings showed that, independent of prey behaviour and movement, the predators are averse to being in close proximity to groups of ants and ant mimics, but have no evident aversion to the close proximity of groups of non-ant-like salticids. Palatability tests demonstrated that the predators fed for long periods on M. melanotarsa, Menemerus and Chaoborus, but released Crematogaster almost immediately. Our results suggest that these predators have an innate aversion to ants and ant mimics and also that they are innately predisposed to perceive a group of ants (or ant mimics) as more repelling than solitary ants or ant mimics. 
Keywords: anti-predator defence; gregariousness; group augmentation; myrmecomorphy; spider; ant; Myrmarachne melanotarsa; Crematogaster. 
In a Batesian-mimicry system, palatable, non-dangerous individuals deceive potential predators by resembling unpalatable or dangerous models. More familiar Batesian mimics (Ruxton et al. 2004) deceitfully adopt the same warning signals by which aposematic prey honestly advertise to predators that they are unpalatable or dangerous. Ants and their mimics (McIver \& Stonedahl 1993) are somewhat different because, although ants may be unpalatable and may be dangerous to many potential predators (Hölldobler \& Wilson 1990; Nelson et al. 2004, 2006a), there is no compelling evidence that the general appearance of ants is a warning signal in the sense of having been shaped for this function by natural selection (i.e., the term 'aposematic' does not normally seem applicable to the ant). This distinction notwithstanding, ant mimics may deceive predators in a manner that is functionally comparable to the way more conventional Batesian mimics deceive predators by resembling aposematic prey (Nelson \& Jackson 2006; Nelson et al. 2006a).

Here we investigate whether, by aggregating, both ants and putative Batesian mimics of ants enhance the aversion that they produce in their predators. We also provide evidence that is consistent with the idea that the predator perceives a group of ant mimics as being a group of ants (collective mimicry).

The particular mimic species we consider is Myrmarachne melanotarsa, a small ant-like jumping spider species (Salticidae) that, whether male or female, adult or juvenile, closely resembles and associates with a similar-size ant, Crematogaster sp. 
(hereafter Crematogaster) (Wesolowska \& Salm 2002). All species in the salticid genus Myrmarachne resemble ants (Reiskind 1977; Edmunds 1978, 2000, 2006), but $M$. melanotarsa is an unusual species from this genus because it lives in nest complexes (individually occupied nests connected to each other by silk) ranging from tens to hundreds of individuals and, whether in or away from its nest complex, M. melanotarsa is normally found in groups (Jackson 1999; Wesolowska \& Salm 2002; Jackson et al. 2008) (Fig. 1).

Two non-ant-like species (another small salticid and a midge) were used as alternative prey in experiments. The predators we used were three large salticid species that are known to be averse to preying on ants. Having unique, complex eyes and exceptional ability to identify prey and enemies from a distance (Land 1969a, b; Williams \& McIntyre 1980; Jackson \& Pollard 1996), salticids are especially suitable as predators in studies related to mimicry. In particular, there are experimental studies showing that many salticids, when relying on vision alone, can identify and avoid ants (Nelson \& Jackson 2006).

The current consensus, based on numerous studies, is that the species in the salticid genus Myrmarachne are Batesian ant mimics (Edmunds 1974, 1993; McIver \& Stonedahl 1993; Foelix 1996; Jackson \& Pollard 1996; Cushing 1997; Ceccarelli \& Crozier 2007; Ceccarelli 2008). For example, mantis and salticid species that are averse to eating ants are also averse to attacking Myrmarachne (Harland \& Jackson 2001; Nelson \& Jackson 2006; Nelson et al. 2006a), whereas the minority of salticid species 
that actively prefer ants as prey also readily eat Myrmarachne (Nelson et al. 2006b). When ant-averse salticids or mantises occasionally attack an ant or an individual of Myrmarachne, they eat the mimic without hesitation but normally they drop the ant without eating it (Harland \& Jackson 2001; Nelson et al. 2006a). However, palatability issues are only part of the problem ants present to salticids. Ants often have formidable defences, such as poison they can deliver with stingers and wounds they can inflict with powerful mandibles (Hölldobler \& Wilson 1990). Ants are also major predators of salticids (Nelson et al. 2004). This combination of factors probably accounts for how innate aversion to ants appears to be widespread among salticids (Nelson \& Jackson 2006).

Earlier research has also shown that, even when only static visual cues are available, the same salticids that are deterred by ants are also deterred by Myrmarachne (Nelson \& Jackson 2006). However, the unique biology of M. melanotarsa gives us an opportunity to investigate something no previous studies have considered - whether predator response to ant-like salticids in groups is comparable to predator response to ants in groups.

We first determined how readily the predators attacked the model (Crematogaster), the mimic (M. melanotarsa) and two non-ant-like arthropods (Menemerus sp. (hereafter Menemerus), a non-ant-like salticid that, like M. melanotarsa, normally lives in aggregations (Jackson 1986a,b) and Chaoborus sp. (hereafter Chaoborus), a midge that is normally found aggregated in the field). We staged 
encounters by the predators with these arthropods, with the arthropod being alone or in a group when presented to the predator. When a predator encounters a group of active, living prey, we can not rule out the possibility that effects other than collective mimicry account for the findings. However, by next determining whether the predators are averse to coming into close proximity to groups of mounts made from dead arthropods from which we removed movement as a variable, we experimentally removed any role of prey behaviour as an influence on test outcome.

\section{METHODS}

Our field site and laboratory were in western Kenya (Mbita Point, $0^{\circ} 25^{\prime} \mathrm{S}-0^{\circ} 30^{\prime} \mathrm{S}$ by $34^{\circ} 10^{\prime} \mathrm{E}-35^{\circ} 15^{\prime} \mathrm{E}, 1200 \mathrm{~m}$ above sea level, mean annual temperature of $27^{\circ} \mathrm{C}$ ) at the Thomas Odhiambo Campus of the International Centre of Insect Physiology and Ecology. Experiments were carried out between 0800 hours and 1300 hours (laboratory photoperiod 12:12 L:D, lights on at 0700 hours). The laboratory-rearing environment for salticids was 'enriched' (spacious cages containing arrays of twigs; see Carducci and Jakob 2000). All salticids came from laboratory cultures (F1 and F2 generation), but insects were collected from the field as needed. No individual of any spider or insect species was used in more than one test and none of the salticids had contact with heterospecific salticids prior to testing.

All body lengths were measured accurate to $0.5 \mathrm{~mm}$. For size standardization, all predators in experiments were juveniles (body length $8 \mathrm{~mm}$ ) (adult body length of these predators, 10-12 mm). Each individual Crematogaster, M. melanotarsa and Menemerus 
was $3 \mathrm{~mm}$ in body length. Each individual Chaoborus midge was $4.5 \mathrm{~mm}$ in body length. The ant mimics were either adult females or juveniles, the non-ant-like salticids were juveniles, the ants were workers, and the midges were adult females. All of the arthropod species used are sympatric in Mbita Point. The three salticid species used as predators do not normally eat ants. Portia africana (hereafter Portia) preys on insects but prefers spiders as prey (Li et al. 1997) and the spiders on which it preys often include other salticids. Hyllus sp. (hereafter Hyllus) and Plexippus sp. (hereafter Plexippus) occasionally prey on other salticids, but primarily prey on insects (RRJ unpubl. data).

We used three types of tests: live-prey tests, mount tests and palatability tests. We ensured that the predators were hungry by keeping them without prey for 15 days prior to testing. We also standardized the feeding condition of all individuals of M. melanotarsa and Menemerus by feeding them to satiation the day before being used as living prey in mount or palatability testing or for making the mounts used in live-prey testing. Regardless of the type of test, all components of the apparatus were cleaned with ethanol followed by distilled water and then allowed to dry between successive tests.

\section{Live-prey tests}

The testing apparatus was a square plastic cage $(100 \times 100 \times 35 \mathrm{~mm}$, length $x$ width $x$ height) with a hole $(10 \mathrm{~mm} \mathrm{~d})$ for introducing prey centred on each side and a hole for introducing the predator centred on the bottom of the cage. Except when introducing the predator or the prey, these holes were kept covered. Ants, ant mimics and 
non-ant-like arthropods were put in the cages 15 min before testing began. Testing began by putting the test spider (i.e., one of the predators) into the cage. This was achieved by taking each test spider into a plastic tube $(10 \mathrm{~mm} \mathrm{~d}$; length $20 \mathrm{~mm})$ at 0830 hours, each end of the tube being plugged with a rubber stopper. Testing began by removing the rubber stopper from the hole in the bottom of the cage and from one end of the tube, and then the open end of the tube was connected to the open hole in the cage. Within 10 min of connecting the tube, the test spider usually walked into the cage. On the rare occasions when the test spider did not spontaneously leave the tube within $10 \mathrm{~min}$, it was gently coaxed out of the tube and into the cage by removing the rubber stopper from the other end of the tube and inserting a small soft brush. The test spider was under continuous observation for the duration of the 60-min test period. Data were analyzed using Fisher exact tests when observed frequencies were low and chi-square tests of independence ( $\alpha$ $=0.05)$ with sequential Bonferroni corrections whenever data sets were compared more than once.

We used single-prey testing (single predator encountered one potential prey individual) and grouped-prey testing (single predator encountered a group of 10 potential prey individuals). With each predator species, single-prey and grouped-prey testing were carried out using Chaoborus, Crematogaster, Menemerus and M. melanotarsa, except that we did not test Portia, the araneophagic predator, with Chaoborus. As M. melanotarsa is often found associated with Crematogaster in the field (Fig. 1), we also carried out three mixed-species grouped-prey tests (M. melanotarsa and Crematogaster in ratios of 5:5, 9:1 and 1:9 when testing with Hyllus and Plexippus, but only 5:5 when 
testing with Portia). With our hypothesis being that the predator does not distinguish between ants and mimics, we predicted that predator response to mixed-species and single-species groups would be comparable.

Ants and midges were collected from the field 45-90 min before testing began. For instances in which more than one ant was present (i.e., in single-species and mixedspecies grouped-prey test), all of the ants comprising the group had been collected in close proximity to each other and most likely each came from the same colony. When more than one individual ant mimic or more than one individual of Menemerus was present in a single-species grouped-prey test, we ensured that they were members of an established group by keeping them together in the test cage for 10 days prior to testing (fed to satiation every second day). All prey, prey remains, nests and visible draglines were removed from the cage containing these salticids at $0830 \mathrm{~h}$ on the morning of testing. For all other testing, the prey was put into the cage until 15 before testing began. This included the ants and mimics for each mixed-species group, as it too was difficult to keep ants alive for more than a few days in the test cage.

As there were no significant differences between predator species, we simplify data presentation by pooling across the three species. (Note: Portia, the araneophagic predator, was not tested using Chaoborus, nor was it tested using 9:1 and 1:9 ratios of Crematogaster and M. melanotarsa, and therefore data for these tests were pooled across only two species). There were no instances in which prey survived after a predator attacked (definition of 'attack': predator leapt or lunged at the prey and, with its 
chelicerae, made contact the prey) and, in the Results, we will generally use the expression 'attack' instead of 'predation' and 'eat'. When we consider data from grouped-prey testing, the expression 'attacked' is used for instances in which the predator killed at least one of the 10 prey individuals. If a predator was holding on to prey when the 60-min test period ended, we continued observation until it released the prey or until a total of 15 min had elapsed after the attack.

\section{Mount tests}

Our methods were adapted from Nelson \& Jackson (2006), with the testing apparatus being a transparent Perspex tube (i.e., the "walkway"), connected at each end to a much wider transparent Perspex tube (i.e., the "chamber") (chamber perpendicular to the walkway). There was a control chamber at one end of the walkway and stimulus chamber at other end (Fig. 2). Each end of each chamber was sealed by the bottom half of a clear plastic Petri dish ( $90 \mathrm{~mm} \mathrm{~d}$, open end of dish away from inside of chamber). A round piece of white filter paper $(90 \mathrm{~mm}$ ) was held in place with transparent tape on the inside top of each Petri dish, and the top of the Petri dish was placed over the bottom piece of the dish and held in place with transparent tape which was itself taped to the bottom of the Petri dish that sealed the chamber (i.e., the side of the dish farthest from the inside of the chamber was white). Only the filter paper was present in the dishes on the ends of the control chamber, but there were four mounts in each of the two dishes on the ends of the stimulus chamber. The eight mounts were always made from individuals of the same size, sex and species. 
To make mounts, the spiders or insects were first immobilised with $\mathrm{CO}_{2}$ and then placed in $80 \%$ ethanol. The next day, each spider or insect was glued in a life-like posture on the centre of a disc-shaped piece of cork (diameter $1.25 \times$ the body length of the spider; thickness $2 \mathrm{~mm}$ ). For preservation, the mount and the cork were then sprayed with a transparent plastic adhesive. Each mount was positioned equidistant from its two nearest neighbours (bottom of cork glued to the filter paper), facing the centre of the paper circle and with its posterior end ca. $20 \mathrm{~mm}$ from the outer edge of the paper.

Whether the stimulus chamber was on the left or right side of the walkway was decided at random for each test. Each test consisted of four successive trials with 20 individual salticids. Tests began at 0800 hours and lasted for $10 \mathrm{~h}$, as earlier research using comparable methods (Nelson \& Jackson 2006) showed that the 10-h period gave the spider time to explore the two chambers and settle in one of them. A 10-mm wide hole in the centre of the top surface of the walkway was used for introducing a test spider at the beginning of each test (rubber stopper in place except when introducing the test spider). The test spider was first taken into a clear glass tube (length $40-\mathrm{mm} ; 8 \mathrm{~mm} \mathrm{~d}$, each end plugged by a rubber stopper) and transferred 10 min later to the walkway by removing the rubber stoppers from the tube and from the hole in the top of the walkway, placing one open end of the tube against the open hole in the walkway and inserting a soft brush through the opposite end of the tube. If the test spider did not immediately enter the walkway, the brush was used as a plunger for gently pushing the salticid out of the tube 
and into the walkway. The salticid's location (i.e., where it 'settled') was recorded at 1800 hours.

After the first trial, the spider was returned to its cage and then tested again one day later. This procedure was repeated until the total of four trials had been completed by each of the 20 test spiders (each test spider from a different brood). Testing was aborted on the rare occasions when, at the end of a 10-h test period, a test spider was found in the walkway instead of being in one of the two chambers.

Over the four trials, each test spider accumulated a score that ranged from 0 for when it never settled in the blank chamber to 4 for when it settled in the blank chamber in four out of four trials (i.e., test spiders with higher scores more often avoided the stimulus chamber). The null hypothesis was that scores would be 2 (i.e., that the test spider was not influenced by what it saw from inside the stimulus chamber). Using SPSS (v.16), Kruskal-Wallis and Wilcoxon signed-ranks tests were applied to the data, with alpha being adjusted whenever multiple comparisons were made using the same dataset.

\section{Palatability tests}

For these tests, we used prey that had been first immobilized (prey taken into vial (10 mm d, length $50 \mathrm{~mm}$ ), vial put in the freezer compartment of a refrigerator for 10 min). By using prey that had been immobilized, we removed variables related to prey behaviour and, in this way, had more success at eliciting attack on ants and ant mimics by 
the predators. Once attacked, we measured latency to release the prey accurate to the nearest minute ('feeding time'). Results were analysed for normality and comparisons were made using Kruskal-Wallis tests.

We adjusted testing methods to accommodate the different predatory styles of the three predator species. Hyllus and Plexippus tend to orient quickly when potential prey moves momentarily in their vicinity and then, after the prey stops moving, stalk and attack the stationary prey. Portia is less inclined to stalk prey that suddenly moves and then becomes immobile, but Portia differs from Hyllus and Plexippus by readily attacking stationary prey encountered under dim light.

\section{Testing Hyllus and Plexippus}

Individuals or Hyllus and Plexippus were first put into cylindrical clear plastic cages ( $50 \mathrm{~mm}$ d, $160 \mathrm{~mm}$ high; one predator per cage) $24 \mathrm{~h}$ before testing began. These predators tend to rest on the sides of the cages, near the top and facing down. Whenever an individual was not quiescent in this position, scheduled testing was postponed.

There was a hole (10 $\mathrm{mm} \mathrm{d}$, plugged with rubber stopper) in the centre of the top of the cage. For starting a test, the stopper was removed, the vial containing the immobilized prey was opened and the prey was quickly tipped out of the vial so that it fell passively past the predator and landed on the floor of the cage. Immediately prior to 
testing, we removed any silk that had accumulated in the cage and that might have impeded the prey falling to the floor.

Observation continued until the predator attacked the prey or the prey began walking. Any prey individual that began walking was removed from the cage. Any predator that attacked the prey was observed until it released the prey. If no attack was made, the predator was left in the cage and testing was repeated the following day (predator not fed during this waiting interval). If the predator had still not attacked the prey after four tests in succession, testing was terminated. Additional predators were tested until a total of 20 attacks were obtained on each prey type. Individual predators were paired with the different prey types at random.

\section{Testing Portia}

The testing protocol using Portia was the same as when testing Hyllus and Plexippus except for the differences stated here. The testing apparatus was in a clear glass tube (15 mm d, length $90 \mathrm{~mm}$, positioned horizontal, rubber stopper in each end). Instead of testing under normal ambient laboratory lighting, we used a lightproof room with the only illumination coming from a halogen lamp (Mickson-Model MF6356, AppN19584, $240 \mathrm{~V}, 50 \mathrm{~Hz}, 20 \mathrm{~W})$ clamped into place directly above the testing apparatus. Light level was set at $0.54 \mathrm{~cd} / \mathrm{m}^{2}$. For creating the dim-light condition, we used neutral density filters (Marumi, ND4 and ND8 filters). Reflected light was measured at the location of the apparatus using an International Light IL 1400 radiometer (in integrated mode). 
Before testing, each individual of Portia was taken into the glass tube and kept there under dim light for an acclimatisation period of $60 \mathrm{~min}$. Testing began by removing the stopper from the end of the tube farthest from the predator and, using a soft brush, pushing the prey to a position $20 \mathrm{~mm}$ from the predator. The stopper was returned and observation was continuous until the predator attacked the prey or the prey began walking. If the predator held on to the prey for $2 \mathrm{~min}$, then normal laboratory lighting was restored and observation continued until the predator released the prey.

\section{RESULTS}

\section{Live-prey tests}

Data for Hyllus, Plexippus and Portia were not significantly different for any test and were subsequently pooled. The predators rarely attacked ants or ant mimics in singleprey tests, rarely attacked ant mimics in single-species grouped-prey tests (Fig. 3) and never attacked ants or ant mimics in mixed-species grouped-prey tests. Significantly fewer Crematogaster (Fisher exact test, $P=0.002$ ) and $M$. melanotarsa (Fisher exact test, $P<0.001)$, but not Menemerus $\left(\chi^{2}=0.864, P=0.353\right)$ or Chaoborus (Fisher exact test, $P$ $=1.00)$, were attacked in grouped-prey tests than in single-prey tests.

Any ant that was attacked was invariably released soon afterwards ( 1 after 10 min; 2 after 6 min; 2 after 2 min; 4 after $<1$ min; Hyllus $(N=3)$, Plexippus $(N=5)$; 
Portia $(N=1)$, but the attacked individuals of the other prey types were always fed on for at least $15 \mathrm{~min}$ (i.e., they were fed on until observation ended).

\section{Mount tests}

For each of three predators, scores differed significantly depending on the type of mount (Kruskal-Wallis test, Hyllus, $H_{2}=28.492 ;$ Plexippus, $H_{2}=24.255 ;$ Portia, $H_{2}=$ 23.815; all $P<0.001)$. Scores were higher than 2 when the stimulus chamber contained ants or ant mimics (Fig. 4), but there was no evidence that the predator's decision to settle in one chamber or another was influenced by seeing mounts made from Menemerus.

For all three predators, scores with ants were not significantly different from scores with ant mimics (Wilcoxon signed-rank tests for pair-wise comparisons: Hyllus, $Z$ $=-0.284, P=0.82 ;$ Plexippus, $Z=-0.101, P=0.95 ;$ Portia $, Z=-1.012, P=0.41)$.

However, the scores of each of the three predators with Menemerus was significantly different from the scores with ants (Hyllus, $Z=-4.553$; Plexippus, $Z=-4.275 ;$ Portia, $Z=$ -4.317; all $P<0.001$ ) and ant mimics (Hyllus, $Z=-4.467$; Plexippus, $Z=-3.973 ;$ Portia, $Z=-3.795 ;$ all $P<0.001$ ) (Fig. 4).

\section{Palatability tests}

Data for each of the four prey types $(\mathrm{N}=20$ per predator), data were not always normally distributed (Kolmogorov-Smirnov test, Crematogaster, $Z=2.850, P<0.001$; 
M. melanotarsa, $Z=0.813, P=0.52 ;$ Menemerus, $Z=1.094, P=0.18$; Chaoborus, $Z=$ $1.241, P=0.09)$.

Mean feeding times for Hyllus, Plexippus and Portia (Fig. 5a) were not significantly different for any prey species (Crematogaster, $H_{2}=5.018, P=0.08 ; M$. melanotarsa, $H_{2}=0.615, P=0.74$; Menemerus sp., $H_{2}=1.773, P=0.41$; Chaoborus sp. $\left.H_{2}=0.912, P=0.63\right)$ and were subsequently pooled. Overall, predator species had no effect on feeding time $\left(H_{2}=0.083, P=0.96\right)$, but feeding time did differ depending on prey type $\left(H_{3}=138.860, P<0.001\right)$; this result was driven by the significantly reduced feeding time on ants (Fig. 5b).

\section{DISCUSSION}

With Myrmarachne melanotarsa, we found no evidence contrary to the consensus view that the ant-like salticids in the genus Myrmarachne are generally Batesian mimics of ants (Edmunds 1974, 1993; McIver \& Stonedahl 1993; Foelix 1996; Jackson \& Pollard 1996; Cushing 1997; Ceccarelli \& Crozier 2007; Ceccarelli 2008). The predators in our experiments (three large salticid species) rarely attacked the ant (Crematogaster) or its mimic (M. melanotarsa). That these predators are averse to attacking the ant and the mimic is consistent with extensive other research showing that salticids tend to be innately averse to attacking ants and also averse to the ant-like salticids from the genus Myrmarachne (Harland \& Jackson 2001, Nelson \& Jackson 2006, Nelson et al. 2006a). 
There is no compelling evidence in support of an alternative hypothesis that $M$. melanotarsa is a Müllerian, instead of a Batesian, mimic of Crematogaster. Being predators and having fangs that can inject venom, perhaps any spider can be envisaged potentially dangerous to other spiders. Yet we used Menemerus, another spider, as an alternative prey and there was no evidence of the predators being reluctant to attack Menemerus. M. melanotarsa actually is a predator of other spiders, but its prey is typically spider eggs and recently hatched juvenile spiders that are smaller than its own size (Jackson et al. 2008) and we have never seen an individual of M. melanotarsa bite or in any other way injure or attack a larger salticid. There is nothing to suggest that $M$. melanotarsa is especially dangerous to the predators we used in our experiments. Nor is there any evidence to suggest that $M$. melanotarsa is unpalatable. The possibility that ant mimicry, which is relatively uncommon in spiders, is due to convergent evolution in the absence of selection pressure from predators is unlikely. Salticidae is the largest family of spiders, and Myrmarachne, containing over 200 described species - all of which are ant mimics - is its largest genus (Proszynski 2009). Myrmarachne is widespread throughout the tropics, as is the case of many non-ant-like spiders. In all cases of ant mimicry studied, both in Myrmarachne and in spiders from other genera, antipredator benefits attributable to ant resemblance have been found (reviewed in McIver \& Stonedahl 1993; Cushing 1997).

Our three representative predators readily attacked the non-ant-like arthropods we used as alternative prey (Chaoborus midges and Menemerus), corroborating our assumption that these are, for Hyllus, Plexippus and Portia, palatable prey. Obtaining 
data on the palatability of the ants and the ant mimics was difficult because these arthropods were rarely attacked, but this problem was not insurmountable. There were rare instances in which the predator attacked M. melanotarsa or Crematogaster during our experiments. In these instances, the ant, but not the mimic, was released soon afterwards. As with the non-ant-like arthropods, the predators spent considerable time feeding on the ant mimics. Using different methods, we increased our number of observations of attacks on ants and ant mimics. Again, although the predators released ants soon after attack, how long they fed on M. melanotarsa was comparable to how long they fed on the non-ant-like arthropods. We see no evidence that would justify any conclusion other than that this ant-like salticid is palatable. With there being no evidence that M. melanotarsa is unpalatable or that this salticid is especially dangerous to the predators we used, there is no strong rationale for a hypothesis that M. melanotarsa is a Müllerian mimic of Crematogaster. Evidently individuals of M. melanotarsa are Batesian mimics of the ant Crematogaster. However, we were more interested in what the predators does upon encountering a group of the ants or a group of the mimics.

Even when the prey in a group of ten individuals were the non-ant-like arthropods (Menemerus and midges), the predators never attacked more than four of the ten group members. Although these findings might suggest questions related to various hypotheses concerning how, by aggregating, prey might gain anti-predator protection (see: Krause \& Ruxton 2002), our data are not adequate for addressing these questions because our test duration was not long enough to allow for feeding on many prey. Nor was this one of our goals. Our objective was, instead, to investigate the collective-mimicry hypothesis by 
comparing how often predators made attacks in single-prey tests with how often predators made attacks in grouped-prey tests.

We found no evidence that predators perceived a group of non-ant-like arthropods as aversive, as how often predators made an attack on a group of non-ant-like prey was comparable to how often they made an attack on single prey. However, fewer attacks were made on the ants or ant mimics in grouped-prey tests than in single-prey tests, regardless of whether it was a single-species or a mixed-species group. These findings suggest that ants and ant mimics were perceived by the predators as more or less identical and that, when a group was identified, either correctly or incorrectly, as a group of ants, it was perceived as more aversive than single prey individuals identified as single ants. These findings are as predicted by the collective-mimicry hypothesis, but there are alternative potential mechanisms by which groups of active, living prey are known to deter predators. For example, it may be that predator confusion, caused by numerous individuals moving about, makes it difficult for the predator to single out, identify and then concentrate on one prey long enough to make an attack (see: Jeschke \& Tollrien 2007, Tosh et al. 2009). In our live-prey experiment, we could not rule out the possibility that something about the way prey behaved in groups deterred the predators independent of the prey being perceived as a group of ants. For example, although we did not record data to document this, the ants and ant mimics in groups appeared to be considerably more active than the non-ant-like prey in groups. This means that, when considering the live-prey tests alone, we can not rule out the possibility that our results are explained entirely by the level of prey activity instead of by the collective-mimicry hypothesis. 
However, mount-test outcomes can not be explained by prey behaviour.

In mount tests, the three predators were deterred by the static appearance of a group of ants or a group of ant mimics in groups, but not by the static appearance of a group of non-ant-like prey. Although aversive stimuli in groups are more aversive than aversive stimuli on their own, our results do not suggest that spiders (that look like spiders) are especially aversive, suggesting that the aversion we found may not merely be an artefact of this effect, but something about ant appearance. However, we are not dismissing the importance of questions about how ant and ant-mimic behaviour might deter predators. Ants have a distinctive locomotory pattern that is imitated by ant-like salticids (Jackson \& Willey 1994; Ceccarelli 2008). That locomotory mimicry (e.g., Golding et al. 2001) is a component of collective mimicry, although not investigated here, is a hypothesis warranting serious consideration.

There has been a strong tradition in the literature of considering Batesian mimicry in the context of predators learning an association between warning signals from aposematic prey and then generalizing to the mimic and this is also true of the literature concerning learned aversion of aversive prey singly and in groups. However, the predators in our experiments had no experience with the models or the mimics and yet aversion was strongly expressed, and more so in groups. We propose that the added aversion is a consequence of what we call 'collective mimicry'. Although there has been extensive previous research on the evolution of gregariousness among aposematic prey and the effect of gregariousness on how Batesian mimicry is expressed (e.g., Mappes \& 
Alatalo 1997a,b; Riipi et al. 2001), our findings seem to pertain to something different (i.e. our findings suggest something like a mimic, by being gregarious, imitates its model's gregariousness).

The term 'collective mimicry' might also be appropriate for Meloe franciscanus (Hafernik \& Saul-Gershenz 2000, Saul-Gershenz \& Millar 2006), but how collective mimicry is expressed in this blister-beetle differs considerably from how collective mimicry appears to be expressed in $M$. melanotarsa. The first-instar juveniles of blisterbeetle larvae, known by the delightful name 'triungulins', form groups consisting of hundreds or thousands of tiny individuals and the group has at least a crude resemblance to a female bee of the species Habropoda pallida. In this instance, however, the interesting function of deceit is to get a ride rather than to deter the unwanted attentions of predator. The mass of triungulins attract $H$. pallida males and, when the male bee makes a futile attempt to mate, the triungulins, as a group, climb on board. When the male bee later encounters a real female bee, the triungulins transfer over to his mate. The triungulins then ride to the female's nest and feed on her eggs. With this example, 'aggressive mimicry', not 'Batesian mimicry', is the appropriate label. Another difference is that the triungulins deceive the male bee not only by having the appearance of a female bee but also by using chemical mimicry (i.e., their odour resembles the odour of the female bee) and chemical mimicry seems to be more important than appearance. However, the primary way in which M. melanotarsa's style of collective mimicry differs from the triungulins' is that the triungulins, as a group, mimic a single individual of the model species, whereas a group of $M$. melanotarsa, as a group, mimics a group of model 
individuals. 


\section{Acknowledgements}

We thank Godfrey Sune, Stephen Alluoch, Silas Ouko Orima and Jane Atieno for technical assistance in Mbita Point, GB Edwards, Wanda Wesolowska, Roy Snelling and Arthur Harrison for taxonomy assistance and Paul $\mathrm{M}^{\mathrm{c}}$ Donald for valuable comments on the manuscript. This research was assisted by grants to RRJ from the Royal Society of New Zealand (Marsden Fund and James Cook Fellowship) and the National Geographic Society. 


\section{References}

Carducci, J. P. \& Jakob, E. M. 2000. Rearing environment affects behaviour of jumping spiders. Animal Behaviour, 59, 39-46. (doi:10.1006/anbe.1999.1282)

Ceccarelli, F. S. 2008. Behavioral mimicry in Myrmarachne species (Araneae, Salticidae) from North Queensland, Australia. Journal of Arachnology, 36, 344351.

Ceccarelli, F. S. \& Crozier, R. H. 2007. Dynamics of the evolution of Batesian mimicry: molecular phylogenetic analysis of ant-mimicking Myrmarachne (Araneae: Salticidae) species and their ant models. Journal of Evolutionary Biology, 20, 286-295.

Cushing, P. E. 1997. Myrmecomorphy and myrmecophily in spiders: a review. Florida Entomologist, 80, 165-193.

Edmunds, M. 1974. Defence in animals: A survey of anti-predator defences. London: Longman.

Edmunds, M. E. 1978. On the association between Myrmarachne spp. (Salticidae) and ants. Bulletin of the British Arachnological Society, 4, 149-60. 
Edmunds, M. E. 1993. Does mimicry of ants reduce predation by wasps on salticid spiders? Memoires of the Queensland Museum, 33, 507-512.

Edmunds, M. E. 2000. Why are there good and poor mimics? Biological Journal of the Linnean Society, 70, 459-466. (doi: 10.1111/j.1095-8312.2000.tb01234.x)

Edmunds, M. E. 2006. Do Malaysian Myrmarachne associate with particular species of ant? Biological Journal of the Linnean Society, 88, 645-653. (doi:10.1111/j.10958312.2006.00649.x)

Foelix, R. F. 1996: Biology of Spiders. New York: Oxford University Press.

Golding, Y. C., Ennos, A. R. \& Edmunds, M. 2001. Similarity in flight behaviour between the honeybee Apis mellifera (Hymenoptera: Apidae) and its presumed mimic, the dronefly Eristalis tenax (Diptera: Syrphidae). Journal of Experimental Biology, 204, 139-145.

Hafernik, J. \& Saul-Gershenz, L. S. 2001. Beetle larvae cooperate to mimic bees. Nature, 405, 35-36

Harland, D. P. \& Jackson, R. R. 2001. Prey classification by Portia fimbriata, a salticid spider that specializes at preying on other salticids: species that elicit cryptic stalking. Journal of Zoology, London, 255, 445-460. 
Hölldobler, B. \& Wilson, E. O. 1990. The ants. Heidelberg: Springer-Verlag.

Jackson, R. R. 1986a. Communal jumping spiders (Araneae: Salticidae) from Kenya: interspecific nest complexes, cohabitation with web-building spiders and intraspecific interactions. New Zealand Journal of Zoology, 13, 13-26.

Jackson, R. R. 1986b. Interspecific interactions of communal jumping spiders (Araneae, Salticidae) from Kenya: mechanisms of sex and species recognition. Behaviour, 97, 297-307.

Jackson, R. R. 1999. Spider cities of Africa. New Zealand Science Monthly, 10, 10-11.

Jackson, R. R. \& Pollard, S. D. 1996. Predatory behavior of jumping spiders. Annual Review of Entomology, 41, 287-308. (doi:10.1146/annurev.en.41.010196.001443)

Jackson, R. R. \& Willey, M. B. 1994. The comparative study of the predatory behaviour of Myrmarachne, ant-like jumping spiders (Araneae, Salticidae). Zoological Journal of the Linnaean Society, 110, 77-102.

Jackson, R. R., Nelson, X. J. \& Salm, K. 2008. The natural history of Myrmarachne melanotarsa, a social ant-mimicking jumping spider. New Zealand Journal of Zoology, 35, 225-235. (doi: 0301-4223/08/3503-0225) 
Jeschke, J. M. \& Tollrian, R. 2007. Prey swarming: which predators become confused and why? Animal Behaviour, 74, 387-392.

Krause, J. \& Ruxton, G. D. 2002. Living in groups. Oxford: Oxford University Press.

Land, M. F. 1969a. Structure of the retinae of the principal eyes of jumping spiders (Salticidae: Dendryphantinae) in relation to visual optics. Journal of Experimental Biology, 51, 443-470.

Land, M. F. 1969b. Movements of the retinae of jumping spiders (Salticidae: Dendryphantinae) in response to visual stimuli. Journal of Experimental Biology, 51, 471-493.

Li, D., Jackson, R. R. \& Barrion, A. T. 1997. Prey preferences of Portia labiata, P. africana, and P. schultzi, araneophagic jumping spiders (Araneae: Salticidae) from the Philippines, Sri Lanka, Kenya and Uganda. New Zealand Journal of Zoology, 24, 333-349.

Mappes, J. \& Alatalo, R. V. 1997a. Effects of novelty and gregariousness in survival of aposematic prey. Behavioral Ecology, 8, 174-177. (doi:10.1093/beheco/8.2.113)

Mappes, J \& Alatalo, R.V. 1997b. Batesian mimicry and signal accuracy. Evolution, 51, 20482051. 
McIver, J. D. \& Stonedahl, G. 1993. Myrmecomorphy: morphological and behavioral mimicry of ants. Annual Review of Entomology, 38, 351-379. (doi:10.1146/annurev.en.38.010193.002031)

Nelson, X. J. \& Jackson, R. R. 2006. Vision-based innate aversion to ants and ant mimics. Behavioral Ecology, 17, 676-681. (doi:10.1093/beheco/ark017)

Nelson, X. J., Li, D. \& Jackson, R. R. 2006b. Out of the frying pan and into the fire: a novel trade-off for Batesian mimics. Ethology, 112, 270-277.

Nelson, X. J., Jackson, R. R., Pollard, S. D., Edwards, G. B. \& Barrion, A. T. 2004. Predation by ants on jumping spiders (Araneae: Salticidae) in the Philippines. New Zealand Journal of Zoology, 31, 45-56. (doi:0301-4223/04/3101-0045)

Nelson, X. J., Jackson, R. R., Li, D., Barrion, A. T. \& Edwards, G. B. 2006a. Innate aversion to ants (Hymenoptera: Formicidae) and ant mimics: experimental findings from mantises. Biological Journal of the Linnean Society, 88, 23-32. (doi:10.1111/j.10958312.2006.00598.x)

Proszynski J. 2009. Catalogue of the Salticidae [online]. http://www.salticidae.org/salticid/main.htm. (accessed 21/03/09) 
Reiskind, J. 1977. Ant-mimicry in Panamanian clubionid and salticid spiders (AraneaeClubionidae, Salticidae). Biotropica, 9, 1-8.

Riipi, M., Alatalo, R. V., Lindström, L. \& Mappes, J. 2001. Multiple benefits of gregariousness cover detectability costs in aposematic aggregations Nature, 413, 512-514. (doi:10.1038/35097061)

Ruxton, G., Sherratt, T. \& Speed, M. 2004. Avoiding attack: The evolutionary ecology of crypsis, warning signals and mimicry. Oxford: Oxford University Press.

Saul-Gershenz, L. S. \& Millar, J. 2006. Phoretic nest parasites use sexual deception to obtain transport to their host's nest. Proceedings of the National Academy of Science (USA), 103, 14039-14044.

Tosh, C. R., Krause, J. \& Ruxton, G. D. 2009. Basic features, conjunctive searches, and the confusion effect in predator-prey interactions. Behaivoral Ecology and Sociobiology, 63, 473-475.

Wesolowska, W. \& Salm, K. 2002. A new species of Myrmarachne from Kenya. Genus, 13, 409-415. 
Williams, D. S. \& McIntyre, P. 1980. The principal eyes of a jumping spider have a telephoto component. Nature, 288, 578-580. (doi:10.1038/288578a0) 


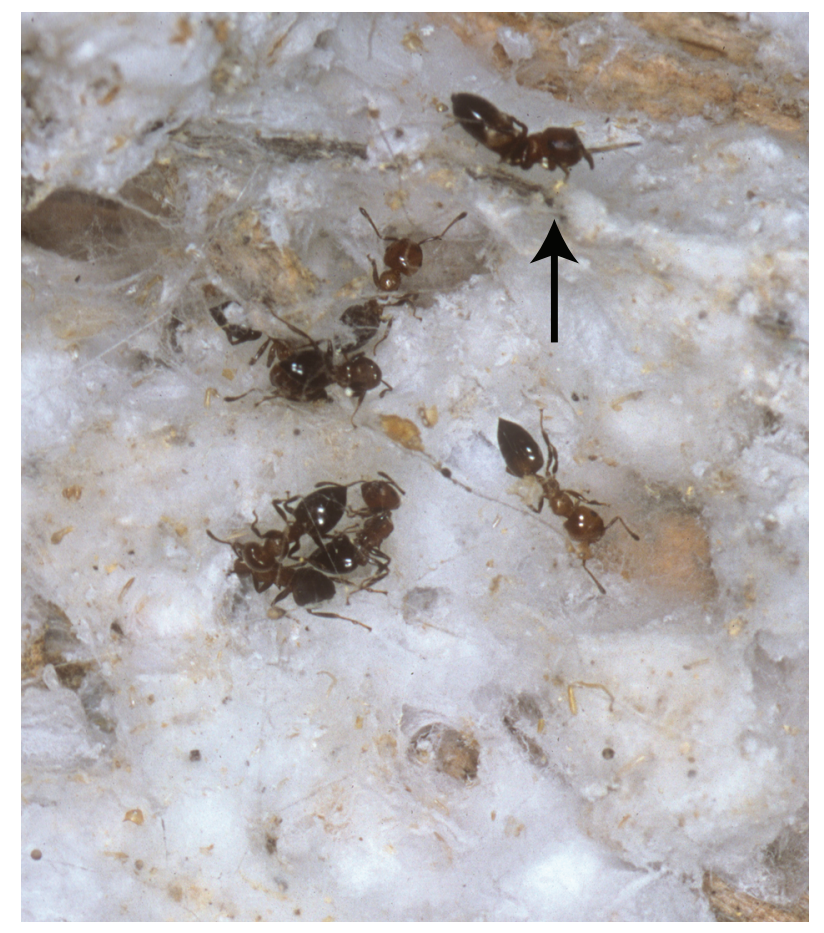

Figure 1. Myrmarachne melanotarsa, an ant-like jumping spider (mimic), and its model, Crematogaster sp. Mimic indicted by arrow. Note multitude of densely packed salticid nests.

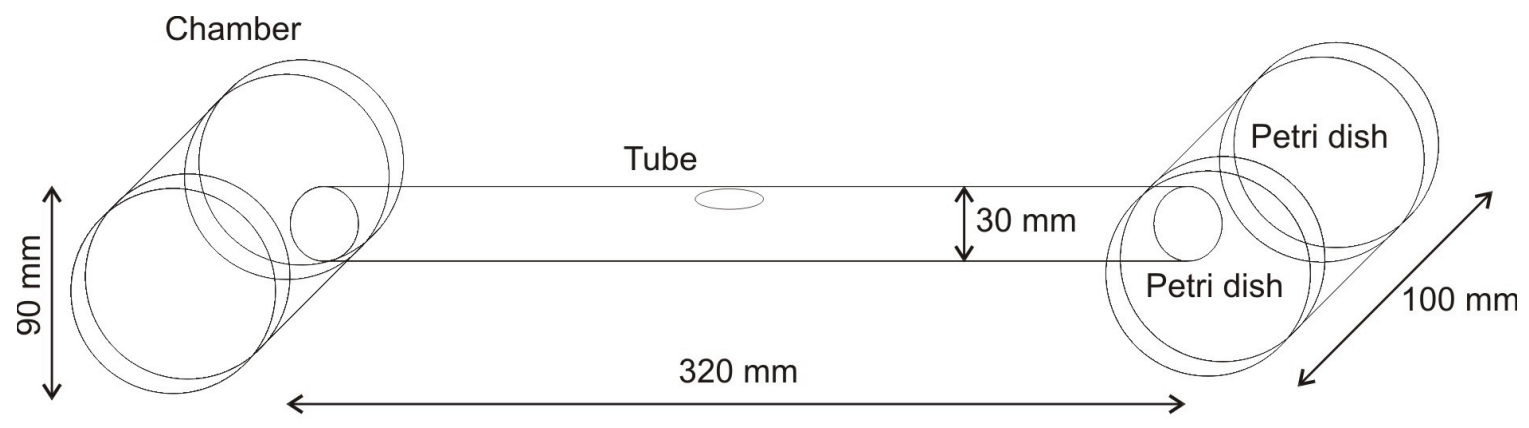

Figure 2. Schematic view of apparatus (cylindrical walkway and two cylindrical chambers made from clear Perspex) used for testing responses of predators to appearance of motionless mounts made from Crematogaster sp. (ants), Myrmarachne melanotarsa (ant-like salticids) and Menemerus sp.(non ant-like salticids). Test spider introduced through hole in middle of walkway. 


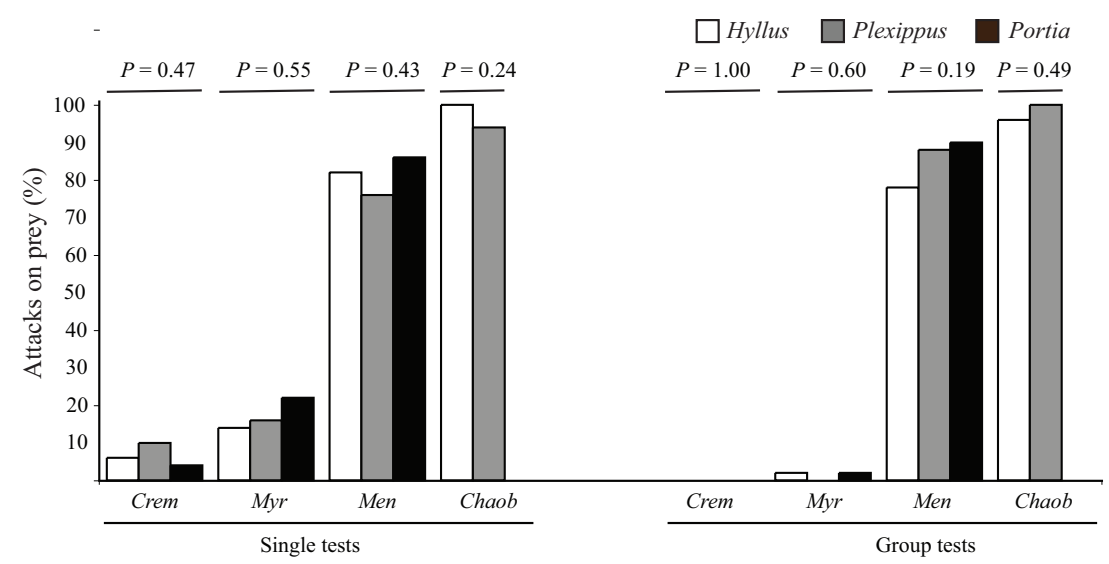

Figure 3. Attacks on ants (Crematogaster sp.: Crem), ant-like salticids (Myrmarachne melanotarsa: Myr), non ant-like salticids (Menemerus sp.: Men) and midges (Chaoborus sp.: Chaob) in single-prey tests and in grouped-prey tests (grouped-prey: 10 individual in each group). Attacks by three predators ( $N=50$ for each predator species), Hyllus sp., Plexippus sp. and Portia africana (P-values above bars are from Fisher exact or chisquare test of independence comparing predation rates of three predators). Attack: at least one individual in the group was attacked by predator. Grouped-prey tests: only data for single-species groups presented. Note: there were no attacks in any mixed-species grouped-prey test. 

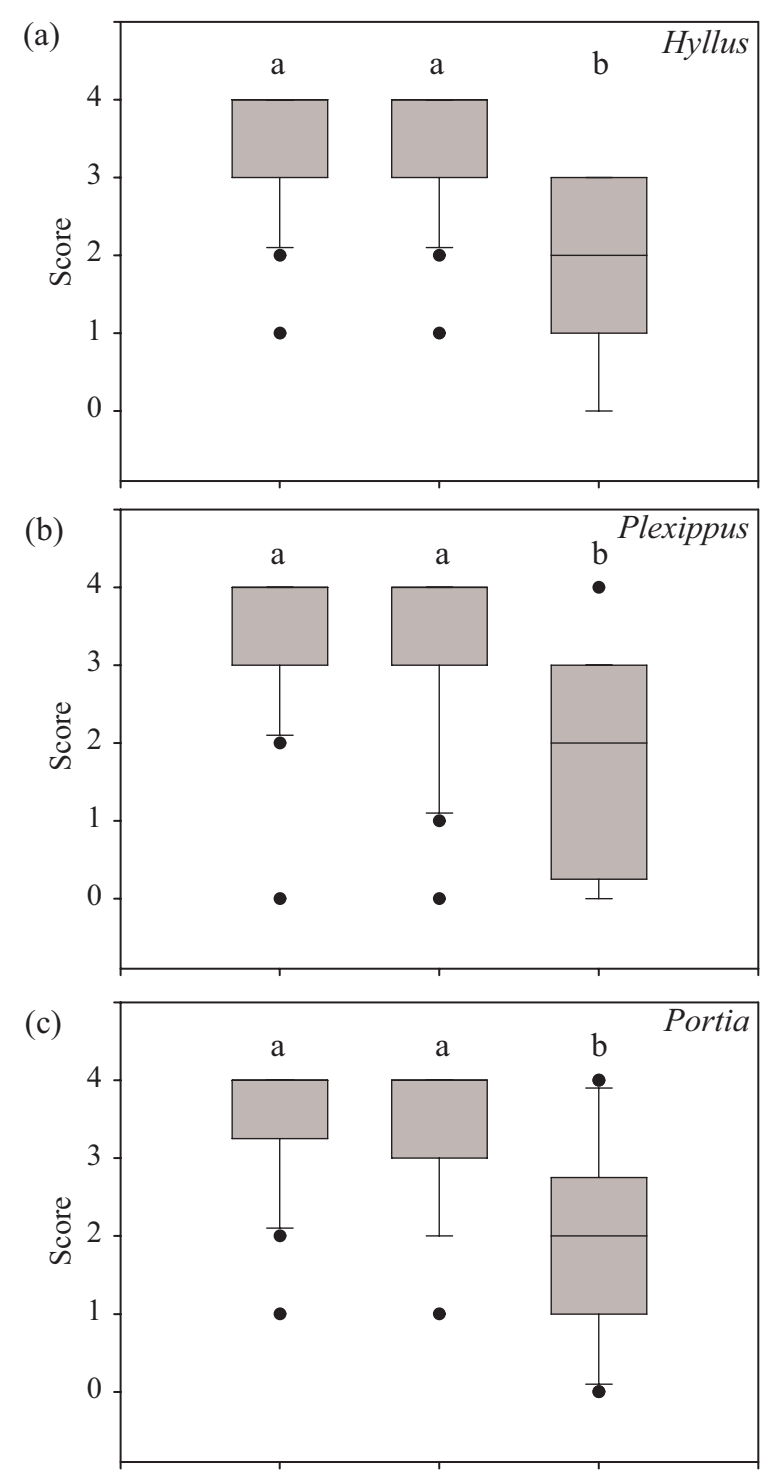

Crematogaster Myrmarachne Menemerus

Figure 4. Boxplots of predators' scores when tested with groups of mount made from Cremtaogaster sp. (ant), Myrmarachne melanotarsa (ant mimic) and, Menemerus sp. (non ant-like salticid). Line in box depicts median and outer edges depict $1^{\text {st }}$ and $3^{\text {rd }}$ quartiles. Whiskers represent $10^{\text {th }}$ and $90^{\text {th }}$ percentiles and circles are outliers. Letters above boxplots denote significant differences $(P<0.001) . N=20$ per stimulus type. (a) Hyllus sp. (b) Plexippus sp. (c) Portia africana. 


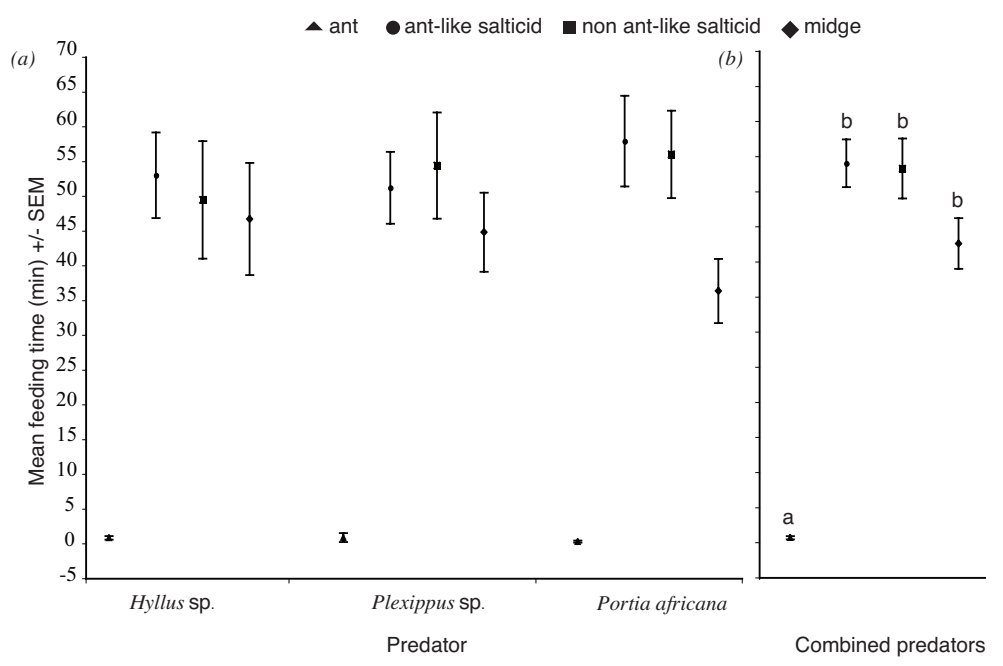

Figure 5. Mean time ( \pm SEM) each of three predators spent feeding on each of four different prey types ( $\mathrm{N}=20$ per prey type). (a) Data for each of three salticid predators. (b) Data pooled across predators. Letters above means denote significant differences $(P<$ $0.001)$. 